\title{
A LUTA DAS MULHERES NO PROCESSO EMANCIPATÓRIO
}

\author{
WOMEN'S STRUGGLE IN EMANCIPATORY PROCESS
}

\section{LA LUCHA DE LAS MUJERES EN EL PROCESO EMANCIPATIVO}

\author{
Jaci de Fátima Souza Candiotto ${ }^{1}$ \\ Maria Rosa da Silva Miranda²
}

\begin{abstract}
Resumo
Defender as mulheres com a dignidade que lhe é devida, pelo fato de ser pessoa e ter nascido igual e livre em direitos, é o princípio que tem impulsionado os movimentos de combate à desigualdade de gênero no planeta, inspirado também nos primeiros artigos da Declaração Universal dos Direitos humanos. O objetivo deste estudo consiste em elaborar uma reflexão teórica capaz de contemplar as práticas emancipatórias das mulheres na luta pela efetivação dos direitos humanos das mulheres. A pesquisa é metodologicamente qualitativa orientada por um referencial teórico bibliográfico, no intuito analítico de avaliar as possibilidades e limites das lutas por emancipação, especialmente de algumas pensadoras que protagonizaram estas lutas. Assim, uma das conclusões a que se chega é que as lutas por emancipação desenrolam-se não somente no plano prático, ou exclusivamente no plano teórico, mas pelo cruzamento entre eles, especialmente quando os movimentos de libertação encontram pontos de apoio e intersecção nas filosofias e teologias da libertação. Uma segunda conclusão é que as lutas por emancipação e igual dignidade encontram-se sempre ameaçadas pela reconfiguração do patriarcado em seus desdobramentos familiar, educacional, religioso e estatal. Por essa razão, a efetivação dos direitos humanos das mulheres não chega a um estágio final somente quando reconhecido publicamente, mas deve ser um objetivo infindável e objeto de uma luta constante.
\end{abstract}

Palavras-chave: Mulheres; Emancipação; Direitos humanos; Participação.

\begin{abstract}
The movement that fights against gender inequality and stands for women, defend them regarding their owned dignity as persons who were born free and equal in rights. These movements are inspired by the Universal Declaration of Human Rights. This article aims at reflecting on women's emancipatory practices in the enforcement of women's rights. This qualitative bibliographical analysis evaluates emancipatory struggles possibilities and limitations, especially considering thinkers who were part of these fights. As a result, the work demonstrates that the outcome of it is not only theoretical or practical, but the main achievements of these struggles are a combination of them. In this regard philosophies and theologies of liberation play a significant role. Another conclusion is that the conquests of dignity and emancipation are constantly under the menace of patriarchy rearrangements in its
\end{abstract}

\footnotetext{
1 Pós-doutorado pelo Institut Catholique de Paris. Doutora em Teologia pela Pontifícia Universidade Católica do Rio de Janeiro. Professora no Programa de Pós-Graduação em Direitos Humanos e Políticas Públicas da Pontifícia Universidade Católica do Paraná.

Contato: jacicandiotto@gmail.com

ORCID: 0000-0002-1780-545X

2 Mestra em Direitos Humanos e Políticas Públicas pela Pontifícia Universidade Católica do Paraná.

Professora da Fundação Instituto Tecnológico Industrial.

Contato: dasilvamrosa@gmail.com
}

ORCID: 0000-0001-6304-7998 
familiar, educational, religious and state outcomes. For this reason, women's rights enforcement never comes to an end, but it is a matter of continuous struggle and everlasting goal.

Keywords: Women; Emancipation; Human Rights; Participation.

\section{Resumen}

Defender a las mujeres con la dignidad que les corresponde por ser persona y por nacer iguales y libres en derechos, es el principio que ha impulsado los movimientos para combatir la desigualdad de género en el planeta, también inspirado en los primeros artículos de la Declaración Universal de Derechos Humanos. El objetivo de este estudio es elaborar una reflexión teórica capaz de contemplar las prácticas emancipadoras de las mujeres en la lucha por la realización de los derechos humanos de las mujeres. La investigación es metodológicamente cualitativa guiada por un marco teórico bibliográfico, con la intención analítica de evaluar las posibilidades y límites de las luchas por la emancipación, especialmente de algunas pensadoras que lideraron estas luchas. Así, una de las conclusiones a las que se llega es que las luchas por la emancipación se dan no solo en el plano práctico, o exclusivamente en el plano teórico, sino a través del cruce entre ellos, especialmente cuando los movimientos de liberación encuentran puntos de apoyo e intersección en las filosofías y teologías de la liberación. Una segunda conclusión es que las luchas por la emancipación y la igual dignidad están siempre amenazadas por la reconfiguración del patriarcado en sus desarrollos familiares, educativos, religiosos y estatales. Por ello, la realización de los derechos humanos de las mujeres no llega a una etapa final solo cuando se reconoce públicamente, sino que debe ser un objetivo sin fin y objeto de constante lucha.

Palabras clave: Mujeres; Emancipación; Derechos Humanos; Participación.

\section{Introdução}

Há que se considerar que o empoderamento das mulheres é condição sine qua non para o desenvolvimento humano de gênero, o que tem levado as agências multilaterais e bilaterais de desenvolvimento e ONGs internacionais a prescrevê-lo como um dos objetivos do desenvolvimento sustentável do Milênio.

Desde a década de 90, o empoderamento das mulheres tornou-se uma das noções "politicamente corretas", imprescindíveis às declarações internacionais (ADJAMAGBO; CALVÈS, 2012, pp. 3-21). Porém, nesse processo de reconhecimento da dívida que a sociedade tem em relação às mulheres, é fato que foram as próprias mulheres mentoras e sujeitos dos movimentos de enfrentamento às desigualdades sofridas por elas.

Na compreensão desse processo emancipatório, torna-se relevante situar a contribuição significativa de mulheres que são críticas de uma mentalidade patriarcal 
que fundamenta tais desigualdade de gênero. Ao relatar sobre a contribuição delas, não significa dissertar somente sobre as suas teorias, mas encontrar os aspectos que reafirmam o olhar para a mulher como ser humano, com a mesma essência que o homem é, compreender criticamente que a sua existência é construída socialmente nas diferentes culturas.

As mudanças econômicas, políticas e sociais, ocorridas na contemporaneidade, tem sido o terreno dos embates das mulheres sobre seu passado cultural de discriminação e invisibilidade. Diante disso, como transformar o presente que ainda não se libertou do passado patriarcal, com seu potencial de invisibilizaçao e desprestígio das mulheres? Como desconstruir essa mentalidade que desemboca em uma negação de sua existência enquanto pessoa possuidora do direito de viver a vida sem violência? Como reconstruir as relações sem qualquer tipo de violência? Como aproveitar o embalo das mudanças para potencializar as lutas feministas?

Diante dessas questões e de todo o amplo terreno das desigualdades de gênero, propomo-nos, com este estudo, elaborar uma reflexão teórica capaz de contemplar as práticas emancipatórias das mulheres na luta pela efetivação dos seus direitos.

A abordagem deste tema é relevante em virtude do contexto patriarcal que marca a história e cultura não só do passado, mas sua persistência na atualidade. É significativo mostrar que a emancipação feminina é resultado de lutas das mulheres e tem dependido, sobretudo, delas as conquistas de seus direitos.

Neste estudo, utilizou-se como estratégia metodológica a revisão bibliográfica. Este tipo de pesquisa tem como finalidade colocar o pesquisador em contato direto com tudo o que foi escrito ou dito sobre determinado tema. Quanto à abordagem, trata-se de uma pesquisa qualitativa.

O objetivo deste artigo é resgatar o papel fundamental de algumas mulheres que protagonizaram o processo emancipatório feminino. 


\section{A cultura do patriarcado e a negação das mulheres}

Segundo a análise da antropóloga, Rose Marie Muraro ${ }^{3}$, em sua obra "A Mulher no Terceiro Milênio" o patriarcado teria sido precedido pelas sociedades matricêntricas, nas quais, a relação entre pais e filhos tinha uma característica peculiar de ternura e, ao mesmo tempo, de grande independência. A criança era educada não para executar tarefas pré-fabricadas para ela, mas para sua autonomia. Com esta compreensão, percebe-se que as relações entre os seres humanos eram mais igualitárias e a participação da mulher dava-se numa relação de partilha e de responsabilidade. Para a autora, as relações macho e fêmea eram esporádicas e, quando existia um "casamento", isto é, uma relação estável, ela não era exclusiva, nem escravizadora de uma das partes. Em contrapartida, o patriarcado remodela as relações humanas em muitas sociedades e culturas (MURARO, 1993, p.33).

Levando em conta que a cultura grega é entendida como o berço da civilização ocidental, esta tem influenciado em muito a forma de pensar as relações humanas e, sobretudo, na construção do estereótipo feminino. Para Aristóteles, a mulher era apenas fêmea, útero, estado incompleto do homem por falta de qualidades (ARISTÓTELES, 2005).

Com essa afirmação, depreende-se a importante tarefa que a mulher assumiu e, atualmente, deve assumir para romper com o preconceito da inferioridade que essa afirmação e outras foram Ihe imprimindo um caráter de subjugação. O homem auto afirmava-se como o ser completo, como essencial e determinava à mulher a categoria de acidental, ser incompleto, inessencial e, portanto, objeto. Essa ideia misogênica dos gregos vai influenciar substancialmente o pensamento medieval religioso, consequentemente marcará o patriarcalismo ocidental que vai estruturar uma sociedade de desiguais em prejuízo, sobretudo das mulheres. Este fardo cultural de invisibilidade da mulher e de negação de suas potencialidades como pessoa humana

\footnotetext{
${ }^{3}$ Rose Marie Muraro foi uma das pioneiras do movimento feminista no país na década de 1970 e popularizou seu pensamento de modo contestador, corajoso e inovador. Discutiu abertamente temas que eram tabus e proibidos naquela época, como sexualidade e corpo, o que lhe rendeu algumas agressões e preconceitos, suplantados por sua personalidade marcante e sensível (ZUCCO; LISBOA, 2014).
} 
é o que a levará ao combate de sua condição subjugada. Historicamente, algumas mulheres sobressaem-se por uma percepção crítica desta mentalidade e, mais recentemente, podem-se destacar movimentos mais organizados que são combativos e propositivos na busca por emancipação e relações mais igualitárias, como, por exemplo, as mulheres na luta por direitos nos espaços da Economia Solidária, a conquista das mulheres nos espaços da Teologia, a organização das mulheres na agroecologia e as mulheres no agronegócio. ${ }^{4}$

Beauvoir, em seu livro Le Deuxième Sexe, afirma que "a mulher não nasce mulher, mas torna-se mulher"5 (BEAUVOIR, 1949, p. 12). Com essa ideia, ele revoluciona a forma de pensar a mulher na sociedade e a própria maneira da mulher pensar em si mesma. Para Beris (2004, p. 165), "a resposta da existencialista Simone de Beauvoir é clara: nenhum ser humano deve ser oprimido ao nascer, seja negro, judeu, proletário ou mulher." 6 Visto que a sociedade ainda é pautada pela visão patriarcal, na qual persistem condicionamentos estruturantes dessa cultura influenciando a educação, a afirmação da filósofa francesa tem sido motivo de grandes reflexões e polêmicas ${ }^{7}$ em vários contextos.

Beauvoir estuda o desenvolvimento psicológico da mulher e os condicionamentos que, ao invés de integrá-la a seu sexo, a tornam alienada, posto que é treinada para ser apêndice do homem. Assim, ela escreve que: "Nenhum destino biológico, psíquico, econômico define a forma que a fêmea humana assume no seio da sociedade; é o conjunto da civilização que elabora esse produto

\footnotetext{
${ }^{4}$ A luta das mulheres e a sua participação na trajetória da humanidade é constante, embora nem sempre foi reconhecida. Na Economia Solidária, o trabalho das mulheres tem resultados significativos no empoderamento de maior consciência do ser feminino com direitos à igualdade de oportunidades e de vivência coletiva cidadã. $\mathrm{Na}$ teologia, as mulheres estão presentes de forma ecumênica em diferentes espaços e lutam para que terminem a dicotomia entre os que possuem as lideranças religiosas estruturadas. Assim como no âmbito da agricultura, as mulheres têm consciência da importância de unir trabalho e superação das diferenças e das desigualdades, a participação das mulheres acontece com toda a expressão dentro destes contextos.

5 "On ne nait pas femme, on le devient" (BEAUVOIR, 1949, p. 12).

6 "La réponse de l'existentialiste Simone Beauvoir est nette: aucun être humain ne doit être opprimé à la naissance, qu'il soit nègre, juif, prolétaire ou femme" (BÉRIS, 2004, p. 165).

7 "Entre os episódios, destaco um que considero prototípico [...]: a moção de repúdio que Simone de Beauvoir recebeu da Câmara Municipal de Campinas em 2015. A filósofa, falecida em 1986, foi rechaçada pelo Poder Legislativo na cidade que abriga este cadernos Pagu, após O Segundo Sexo ser, tema de questão do Exame Nacional de Ensino Médio (Enem). O caso expõe como se constituem as iniciativas contrárias a gênero, quais são as argumentações utilizadas para sustentá-las e quem são seus atores" (MANO, 2019, p.04).
} 
intermediário entre o macho e o castrado que qualifica de feminino" (BEAUVOIR, 1980, p.99). Dessa forma, a sociedade define o gênero de cada ser humano e isso não pode ser tomado como algo natural, biológico, mas sim definido socialmente. A filósofa tenta desconstruir essa ideia de natural e busca a igualdade entre os gêneros, demonstrando que mulheres e homens devem ter os mesmos direitos.

Simone de Beauvoir, ainda na primeira metade do século $X X$, coloca o ser mulher como um sujeito-em-si, resgatando-o de um mero reflexo invertido ou de uma construção do olhar masculino. A autora reafirma a revolucionária percepção de que mulheres são sujeitos da história e sujeitos de suas histórias. Para ela, a posição que a mulher é determinada a ocupar na sociedade ou nas relações de submissão, dentro espaço privado, carrega as marcas de uma cultura de poder que foi sedimentada por um período muito mais longo que a luta pelos direitos humanos e pela busca emancipatória, principalmente com relação às mulheres.

Convém ressaltar que a discussão moderna sobre a posição da mulher nas diferentes sociedades vem sendo travada desde o século XVIII. Por mais importante que seja para a trajetória das mulheres, ela não deve ser entendida como um fenômeno exclusivo do século $X X$, época em que a visibilidade da ação feminina foi importante e também foi um tempo em que mais estendeu cidadania e direitos às mulheres em geral.

O século XX é considerado um século que marcou profundamente a história da humanidade e, por isso, é conhecido com vários rótulos. Entre alguns mais comuns encontramos,

o mais assassino da história humana, de acordo com o historiador inglês J. Hobsbawn. Ou então como o século das inquietudes e do domínio do dinheiro, de acordo com o sociólogo francês E. Enriquez. ou ainda, de acordo com o filósofo francês $C$. Castoriadis, o século $X X$ foi aquele em que houve o triunfo da ciência. Mas poderíamos acrescentar a essa lista outro rótulo: de fato, o século XX foi também o século das mulheres (FREITAS, 2006, p. 01).

Com efeito, o século XX pode ser considerado o século das mulheres porque uma revolução silenciosa, mas intensa, transformou radicalmente as condições de vida das mulheres (FREITAS, 2006). O protagonismo das mulheres representou a reorganização da forma de pensar os papéis femininos na sociedade. De fato, foi a revolução sem partidos políticos e sem grandes ideologias de dominação. A 
mulher mudou a face da sociedade humana e trouxe consequências expressivas nas várias dimensões como, por exemplo, da vida familiar, da vida socioeconômica, da política e cultural dos povos, questionando suas tradições, seus modos e costumes.

Pode-se afirmar que Beauvoir é considerada uma das mulheres que contribuíram significativamente para as transformações dos valores e tradições que eram estabelecidos desde a lógica do poder patriarcal. Contribuiu pessoalmente no seu contexto social e também para o desenvolvimento de organizações feministas e, ainda, vem contribuindo com o seu pensamento para a construção de novas formas de interpretação do ser mulher. A partir da sua análise, entende-se que existe, entre outros elementos, uma denúncia à mentalidade patriarcal construída no decorrer da história.

Vale destacar que Simone de Beauvoir representou a retomada de pensamentos novos, dando continuidade aos processos de libertação e de participação da mulher em diferentes contextos da sociedade francesa. Mesmo sendo vista de início como uma mulher de ideias complexas e de uma tendência mais poética que filosófica, não deixou que a subjugassem ao âmbito do puro idealismo. Se ela viveu ou não relações mais igualitárias não seria possível assegurar, porém, o que se sabe é que ela foi corajosa o suficiente para implantar uma nova forma de pensar a existência da mulher no mundo. Caminhou pela história explorando as possibilidades do existir humano. Esteve ao lado de outras mulheres e homens ${ }^{8}$ e s destacou-se com a sua capacidade, deixando o seu legado junto a outros intelectuais.

É preciso entender a importância de Beauvoir como herdeira de uma tradição de engajamento nas causas femininas, que se originava dos tempos da Revolução Francesa de 1789, quando mulheres como Theroigine de Méricourt, que fundara 0 clube misto dos Amigos da Lei em 1790 e Olympe de Gouges (1748-1793), redigira a Déclaration des droits de la femme et de la citoyenne ${ }^{9}$, de 1791, (Declaração dos

\footnotetext{
8 Simone também foi editora da revista "Les Temps Modernes", que fundou junto com Sartre em 1945. O nome da revista refere-se ao filme de Charles Chaplin. Ela fez parte da segunda onda feminista e sua obra "O Segundo Sexo" foi publicado em 1949, o qual tem repercussão até hoje. Beauvoir esteve ao lado de homens e mulheres: Jean-Paul Sartre, Gertrude Stein, Mary Wollstonecraft, Virginia Woolf, Ursula K. Le Guin, pessoas, entre outras, que nos deixaram um legado intelectual e práticas que nos impulsionam a seguir a trajetória das lutas por uma sociedade de maior respeito à diversidade.

9 Dois anos depois da Revolução, em 1791, Olympe de Gouges ousa propor uma Declaração dos direitos da mulher e da cidadã. O documento é encaminhado à Assembleia Nacional da França, para que fosse aprovado, como havia ocorrido com a Declaração dos Direitos do Homem e do Cidadão
} 
Direitos da Mulher Cidadã) encaminhado à Assembleia Nacional da França, em 1971, pedindo que o documento fosse tomado como fundamento da Constituição. Foi o primeiro documento histórico a reclamar abertamente os direitos iguais para homens e mulheres.

As intervenções de Olympe de Gouges repercutiram na sociedade francesa e a levaram à morte na guilhotina em 1793. Ao escrever e publicar a Declaração da mulher, universalmente reconhecida como fundadora dos modernos direitos à liberdade e à igualdade, ela manifestou nos seguintes termos seu inconformismo com a discriminação da mulher: "A mulher tem o direito de subir no cadafalso; deve ter também o direito de subir a uma tribuna" (GOUGES, 1791, Art. X). Com esta postura, percebe-se que havia na sociedade francesa mulheres que eram determinadas $e$ reconheciam o potencial que podiam exercer na esfera pública.

A Declaração dos Direitos da Mulher e da Cidadã (1791) é um documento que contempla, até os dias atuais, a exigência de efetivação dos direitos da mulher. Reconhecendo a importância de sua validade, subscrevem-se aqui alguns artigos:

\begin{abstract}
Artigo segundo - O objetivo de toda associação política é a conservação dos direitos naturais e imprescritíveis da Mulher e do Homem. Estes direitos são a liberdade, a propriedade, a segurança, e, sobretudo, a resistência à opressão. Artigo quarto - A liberdade e a justiça consistem em restituir tudo que pertence a outrem. Sendo assim, o exercício dos direitos naturais da mulher não tem outros limites senão a perpétua tirania que o homem lhe impõe; estes limites devem ser reformados pelas leis da natureza e da razão (ASSMANN, 2007, p. 2).
\end{abstract}

Entre tantas mulheres de destaque na luta pela emancipação e pela defesa de direitos, há também Flora Tristan (1803-1844), referência importante para o movimento feminista. Ela foi a primeira a defender a necessidade de organizar os proletários em nível internacional, levando em conta a opressão das mulheres. Militante socialista, autora da obra "Peregrinações de uma Pária", escritos que foram resultados de suas viagens por América e Europa e que foram publicados em 1838, nos quais a autora já apresentava uma escrita cuja preocupação era a condição da mulher. Embora com a preocupação também com as desigualdades presentes na

(agosto de 1789). Esta declaração, conhecida de todos nós, praticamente inspira os 30 artigos da Declaração Universal dos Direitos Humanos, aprovada pela ONU em 1948. 
sociedade, Flora tinha uma escrita fortemente feminista. Defensora da igualdade de operários e operárias, travou uma luta que teve continuidade na formação dos Batalhões Femininos da República, que saíram às ruas da França na defesa do cumprimento da Lei Ferry ${ }^{10}$ de 1881 , que determinava o acesso das mulheres ao ensino público.

No transcurso da segunda metade do século XX até os dias atuais, as reflexões relacionadas à cidadania e às reivindicações por relações menos opressoras são reforçadas pelo princípio da igualdade de todos os seres humanos. Esse princípio deve ser complementado com o reconhecimento do chamado direito à diferença.

Há que se mencionar, ainda, que a ideologia dominante de vários contextos sociais, legitimados pelo poder da burguesia, por tendências religiosas, correntes filosóficas e teorias científicas, por muito tempo entendiam que a dignidade humana consistia sempre em considerar e tratar o outro, um indivíduo, uma classe social, um povo - como inferior ou superior. Isso se dava sob pretexto da diferença natural. Um exemplo, que é publicamente verificado, é de que o homem tem características naturalmente superiores à mulher. Também eram relevantes as diferenças de etnia, gênero, costumes ou fortuna patrimonial casadas com o poder político.

Diversas manifestações voltadas para a luta das mulheres marcaram o século XIX e, principalmente, o século XX. Sabe-se que a presença delas nas organizações de defesa dos Direitos marca a trajetória de superação de relações opressoras.

Em 1868, no Brasil imperial e escravocrata, foi publicado por uma mulher um documento intitulado "Tratado sobre emancipação política da mulher e direito de votar", que reivindicava o direito das mulheres de participar da política, do mercado de trabalho e da educação e também defendia o voto feminino. A principal denúncia encontrada nele diz respeito à educação das mulheres. A autora que assina o manifesto sob a sigla A.R.T.S. demonstra que o mito do homem mais inteligente do que a mulher é apenas uma consequência da educação, à qual cada pessoa tem acesso. Só a educação faz a diferença, afirma a autora, dizendo que a mulher é deserdada da natureza; é destituída do espírito de invenção, que nada tem produzido.

\footnotetext{
10 Jules Ferry (1832-1893) foi um advogado, jornalista, diplomata e político francês. Como Ministro da educação, foi quem tornou a escola francesa laica (ou seja, religiosamente neutra) e (politicamente) republicana.
} 
A educação da mulher presentemente pende mais para uma informação superficial dos objetos sólidos, do que para uma sólida instrução. Muitas cousas são ensinadas à mulher, nenhuma com perfeição. [...]. (A.R.T.S. 1868$, p. 73$)$.

Embora essa obra seja importante para as lutas emancipatórias das mulheres, ela é quase desconhecida. Foi publicada pela editora do tipógrafo Francisco de Paula Brito e não se sabe sobre sua autoria e circulação. O contexto da publicação é excludente em relação às mulheres, o que justifica sua invisibilidade e a negação de seu acesso à educação formal. Era recorrente desqualificar, portanto, suas produções (Cf. RIBEIRO, 2017, p. 03).

No Brasil, a mulher encontrava-se subjugada a obedecer às ordens dos que eram "seus tutores". Com o processo de construção das democracias, os debates são ampliados e a educação passa a ser questionada. A condição de cidadão e cidadã brasileiro/a foi-se construindo lentamente. A cidadania, como se concebe hoje, só tomou forma com a Constituição de 1988, a chamada Constituição Cidadã. Então, pensar a mulher brasileira é, antes de tudo, pensar a mulher no Brasil com toda a diversidade cultural, desde a mulher nativa, a mulher negra como a europeia até os dias atuais com toda a influência migratória.

A luta das mulheres, de modo geral, é entendida a partir dos vários contextos: social, econômico, político e religioso em que vive o povo todo. Pensar a mulher é considerar esses vários contextos e, também, as várias etnias que conformam o cenário latino americano, com todas as características que vão contribuindo e transformando a cultura ao longo dos anos. A luta das mulheres e suas organizações estão permeadas com as lutas de todo um povo trabalhador, que traz consigo o estigma provocado pelas desigualdades socioeconômicas.

Historicamente, a mulher é vista com uma postura passiva e obediente sob a influência de uma educação voltada para o respeito às ordens dadas pelo senhor da casa, que por sua vez, encontrava a legitimação na própria religião. O que contrariava aos padrões de comportamento e de instrução da época impactava toda a sociedade e era motivo de escândalo. Um exemplo disso foi o reconhecimento profissional de Maria Augusta Generosa Estrela, que teve repercussão indo parar na imprensa e causou grande impacto. Esse fato foi uma forma de contribuir para a alteração dos critérios de ingresso de mulheres nos cursos superiores. 


\begin{abstract}
A primeira grande matriz da educação na segunda metade do século XIX é o Decreto Couto Ferraz, de 1854. O Decreto Leôncio de Carvalho, de 1879, retoma as preocupações do projeto de lei de João Alfredo, acentuando a justificação doutrinária e também ele fazendo um novo e importante deslocamento argumentativo, novamente rompendo com a tradição do Império. Se este justificou, ao longo de suas muitas décadas, a ampliação da educação como exigência de formar eleitores, o último decreto o fará por razões sociais, sejam elas assistenciais ao povo pobre, sejam em decorrência da percepção de ameaças que a pobreza das massas possa trazer às elites (ROCHA, 2010, p. 03).
\end{abstract}

Essa reforma no ensino aprovada no parlamento permitiu a matrícula de mulheres nas faculdades (SCHUMAHER; BRAZIL, 2000). Essas mulheres foram protagonistas e representam o potencial de muitas outras que são desafiadas a ter as mesmas posturas de questionar as estruturas estabelecidas e ocupar os espaços que também Ihes pertencem.

Especializar-se e organizar-se era, sem dúvida, a meta que muitas mulheres propunham, pois nem todas aceitavam permanecer na condição de submissão. No entanto, as dificuldades eram muitas, a estruturação, a diversidade entre elas mesmas, como: étnica (a mulher nativa, negra, europeia), condição socioeconômica, orientação sexual, faixa etária, todas as expressões próprias da cultura e também algumas abordagens de participação política e principalmente abordagens vindas da concepção patriarcal.

Nesse contexto, a educação das mulheres tinha a predominância da ideologia machista para a qual às mulheres estava destinada educação dos filhos e a manutenção dos padrões morais adequados às famílias tradicionais. Essa batalha das mulheres contra as estruturas impostas por uma sociedade pensada a partir do sexo masculino tem instigado e impulsionado os movimentos de mulheres e os feminismos. $\mathrm{Na}$ trajetória histórica desses movimentos, não foram poucas as lideranças que protagonizaram essas verdadeiras "batalhas" contra uma mentalidade excludente das mulheres. Suas lutas objetivavam a defesa dos Direitos Humanos e a emancipação feminina.

Esses Direitos englobavam tanto os civis como os sociais. Os Direitos civis (liberdade religiosa, liberdade de pensamento, direito de ir e vir, propriedade, trabalho, etc.) tornavam mais difíceis a sua efetivação por conta da restrição que se fazia à mulher, privando-a do espaço público. Com relação aos direitos sociais (direito à educação básica, assistência à saúde, programas habitacionais, etc.), estes 
acabavam ficando com certo ordenamento e assistência em mãos privadas ou sob responsabilidade da Igreja.

Por vários séculos, o legado colonial, principalmente da escravidão, continuou presente nas sociedades latino-americanas. Diante disso, os valores de liberdade praticamente inexistiam na sociedade escravocrata e pouco significavam para a maioria da população. Os direitos civis só existiam no papel. Se a maioria estava abaixo da lei, os senhores coronéis estavam acima dela. Os direitos de ir e vir e de propriedade, a inviolabilidade de domicílio e a proteção da integridade física dependiam do poder dos coronéis (CARVALHO, 2011). Ademais, as eleições eram controladas por eles ou pelas oligarquias regionais, o que significava que a decisão do voto estava na mão de quem tinha o poder. Era o chamado "voto de cabresto". Nesse sentido, as pessoas eram conduzidas pelo poder de mando concentrado econômico e politicamente pelas autoridades.

Não podemos negar que muitas mulheres estavam conscientes de que era possível mudar, a partir delas mesmas, as diferentes realidades de opressão. Destaca-se como defensora da mulher negra Bertha Maria Julia Lutz (1894-1976) ${ }^{11}$, cientista, líder feminista e política paulista. Ela foi uma das principais lideranças do Movimento Sufragista.

Após a morte de Cândido Pessoa, Bertha assumiu a vaga de deputada federal e apresentou o projeto do Estatuto da Mulher para a reformulação da lei sobre o trabalho feminino e para a criação do Departamento da Mulher. Este último teve a oposição de Carlota Pereira de Queirós (1892-1982) ${ }^{12}$, médica, escritora, pedagoga e política brasileira, que deu enorme contribuição para a mudança do modo de pensar da mulher brasileira

Carlota foi a primeira deputada federal da história do Brasil, eleita pelo Estado de São Paulo, em 1933, para uma das 254 cadeiras da Câmara dos Deputados à Assembleia Nacional Constituinte de 1934. Na Constituinte, Carlota integrou a

\footnotetext{
11 Cientista, líder feminista e política paulista (1894-1976). É uma das pioneiras da luta pelo voto feminino e pela igualdade de direitos entre homens e mulheres no país.

12 Carlota Pereira de Queiroz, diplomada pela Escola-Modelo Caetano de Campos em 1909, foi a primeira mulher eleita deputada em São Paulo. Permaneceu na Câmara dos Deputados até 1937, quando o golpe de estado impetrado por Getúlio determinou o fechamento de todas as casas legislativas do país. Foi o mais longo recesso parlamentar de nossa história. Durante o Estado Novo (1937-1945), Carlota lutou ativamente pela redemocratização do país (SCHPUN, 1997, p. 167-200).
} 
Comissão de Saúde e Educação, trabalhando pela alfabetização e assistência social, sendo a voz de muitas mulheres. Foi membro das Associações Paulista de Medicina de São Paulo, "Association Françaisepourl Étudedu Câncer", Academia Nacional de Medicina e Academia Nacional de Medicina de Buenos Aires. Fundou a Academia Brasileira de Mulheres Médicas, em1950, e faleceu em São Paulo, em 14 de abril de 1982, aos 90 anos (BALIERO, 2014).

Devido a sua influência como deputada, participou dos trabalhos na Assembleia Nacional Constituinte, entre 1934 e 1935, e defendia que deveriam ser equiparados os direitos dos homens e das mulheres em todas as dimensões, inclusive no político. Para Carlota, criar algo específico, voltado só para as mulheres, como uma proposta particularmente feminina como queria Bertha Lutz, estaria ferindo o princípio de equidade e representava um ato de discriminação sexual.

De acordo com Soihet (2000), Bertha Lutz, a mulher que nos anos 20-30 esteve envolvida com o protagonismo das mulheres e possibilitou novas relações, enfrentou várias críticas em suas iniciativas, principalmente com a forma como pensava o feminismo, não sendo bem entendida. Deparou-se com vários argumentos que afirmavam ser um feminismo de elite, muito conservador, bem-comportado, jurídicoinstitucional, porém apresenta um destacado cenário na sua trajetória, que une as iniciativas e práticas feministas/científico-política. Ela lutou pelo direito das brasileiras ao voto e, quando candidata, propôs o direito à licença maternidade. Era uma época de valorização no país das atividades científicas, educacionais, de institucionalização das profissões acadêmicas e de progressiva busca por sua maior internacionalização, com forte referência aos Estados Unidos. Era o momento de pensar e agir de forma que a mulher brasileira pudesse ocupar o espaço que de direito era dela.

Referindo-se à Bertha, Soihet relata que:

\footnotetext{
Ainda em fins de 1918, Bertha envia uma carta à Revista da Semana, na qual se observa este duplo movimento. Critica os homens pelo tratamento dispensado às mulheres, que, sob a capa do respeito, tentavam mantê-las em permanente estado de infantilização. Exige o direito de ser respeitada como ser humano e não como objeto de luxo ou agrado, incapaz de pensar por si. Reconhece, porém, não serem eles os únicos responsáveis pelo estágio em que se encontrava a condição feminina, embora tivessem uma grande parcela, já que 'a legislação, a política e todas as instituições públicas' estão em suas mãos. Cabia, contudo, às mulheres lutarem pela sua emancipação, como o fizeram as inglesas e as americanas. $E$ tal luta demandava requisitos básicos, tais como espírito de iniciativa,
} 
exercício do trabalho e educação. O exercício do trabalho era determinante, porque thes propiciava meios de subsistência, livrando-as de uma 'dependência humilhante'. Constituía, além disso, fator decisivo no amadurecimento da personalidade feminina, ajudando-a a 'disciplinar a vontade e educar o pensamento'. A educação seria o veículo para a consecução desse objetivo (SOIHET, 2000, p. 100).

Para Bertha Lutz, as mulheres não precisam apenas de assistência social, mas também melhores condições de trabalho e de vida. Em 1919, ela fundou a Aliança de Libertação Intelectual das Mulheres com um grupo de companheiras, cujo objetivo era reconhecer os direitos das mulheres e sua ampla participação na vida pública, contribuindo assim para a libertação e o desenvolvimento delas. Muitas de suas proposições estão compiladas no livro "13 Princípios Básicos da Constituição", editado pelo Departamento de Pesquisas Jurídicas da Federação Brasileira do Progresso Feminino (FBPF). Tais propostas foram aceitas e incorporadas à legislação brasileira. As sugestões, muitas das quais já discutidas em congressos feministas anteriores, defendiam os direitos políticos e jurídicos das mulheres em geral, com atenção especial às questões relacionadas ao trabalho, educação, maternidade e infância. Quando a ONU instituiu 1975 como o Ano Internacional da Mulher, por indicação do movimento feminista internacional, Berta Lutz foi convidada a participar da delegação do Brasil no I Congresso Internacional da Mulher, no México ((SCHUMAHER; BRAZIL, $2000 \mathrm{~s} / \mathrm{p})$.

Com a implantação do decreto do Estado Novo no Brasil, a carreira política de Bertha parece chegar ao fim. Houve uma redução da capacidade de mobilização da FBPF, organização que dava suporte às lutas das mulheres, fundado por Carmen Velasco Portinho (1903 - 2001). Essa mulher engenheira, que teve uma atuação importante para com a inserção e permanência das mulheres nas faculdades na década de 1930, pôde contar com o apoio da União Universitária Feminina, organização que integrava várias mulheres como: Heloísa Marinho (1903-1994) formada em filosofia pela Universidade de Chicago, que se encontrava na diretoria; Orminda Bastos (1899-1971), advogada; Natércia da Silveira também advogada e Amélia Sapienza, engenheira. Integravam a Comissão do Conselho: Bertha Lutz, Joana Lopez, que era médica cirurgiã; Mirtes de Campos, advogada; Erbina de Assis, médica; Emília Snethlage, doutora em ciências. A União Universitária Feminina era presidida por Carmem Velasco Portinho, que era uma das "sufragistas", isto 
é, mulheres que lutaram pelo direito ao voto feminino e estiveram mais próximas de Bertha Lutz. Por isso que o apoio de Carmen e de outras tantas mulheres deu a Bertha as possibilidades de continuar. Ela manteve-se na luta representando o Brasil em várias oportunidades e participando como membro de entidades internacionais. Diante desse contexto,

\begin{abstract}
surgem filiais da FBPF em diversos estados, assim como outras associações assistenciais e profissionais unem-se à referida entidade. Conferências, crônicas de Bertha e de outras líderes procuram manter a questão do voto feminino na ordem do dia. Em maio de 1923, Bertha Lutz representou FBPF no 9 Congresso Internacional pelo Sufrágio, reunido em Roma, participando o Brasil pela primeira vez de uma reunião internacional feminina, abrangendo países dos dois hemisférios. Bertha Lutz sugeriu a substituição das expressões 'igualdade dos sexos' e 'direitos da mulher' respectivamente por 'equivalência dos sexos' e 'novas responsabilidades da mulher', deixando entrever uma tática nova mais comedida, que ela acreditava mais adequada à consecução dos objetivos visados. Acrescentou, em seguida, que a participação da mulher não implicava competição e sim colaboração (SOIHET, 2000, p. 28).
\end{abstract}

É importante ressaltar que o cenário do trabalho feminino apresentou-se à Bertha Lutz como um dos problemas a ser pensado e resolvido no desenrolar do processo de emancipação, inclusive aquele das mulheres pobres. Diante disso, Bertha sugeriu a criação de associações de classe para as diversas categorias profissionais. No começo de seu trabalho, aparece como uma das fundadoras da "Legião da Mulher Brasileira", que era uma espécie de "Associação das Mulheres", que, por necessidade ou por princípio, já trabalhava e enfrentava corajosamente a luta diária.

Em 1922, a participação efetiva de Bertha fez-se sentir em favor das empregadas no comércio, intercedendo junto ao Conselho Municipal para a redução do horário de trabalho de treze a quatorze horas diárias, para oito horas. Ainda nesse mesmo ano, reconhecendo as dificuldades das mulheres trabalhadoras e a sua necessidade de autossuficiência econômica que garantisse sua emancipação, as mulheres que já militavam na Federação Brasileira Pelo Progresso Feminino (FBPF), defendiam a criação de creches, exigindo que não pese apenas sobre a mulher a responsabilidade dos filhos. Era necessário proporcionar-lhes os meios de alcançar a independência por meio do trabalho e da educação e,

$$
\text { merece destaque a atuação da Federação Brasileira Pelo }
$$


Progresso Feminino, fundada em 1922 e tendo como principal bandeira de luta a busca pelo sufrágio universal. Com sede no Rio de Janeiro, então capital do País, a Federação, que tinha como presidente Bertha Lutz, possuía uma rede de relações significativas e discutiam em seus congressos diversos temas, como a nacionalização do ensino público, a educação doméstica, o ensino primário, a formação para o magistério, o ensino secundário e o superior para as mulheres (MOTTA, 2014, p 02)

As formas de organizações e reivindicações das mulheres no passado contribuíram significativamente para as nossas conquistas hoje.

\section{A educação como possibilidade efetiva de emancipação}

O século XX ficou marcado como o período que mais se falou sobre os Direitos Humanos a nível internacional e o Brasil aderiu a esses Pactos e Protocolos. Cabe ressaltar que, no contexto brasileiro, no que diz respeito às mulheres, estas se organizaram e, mesmo em um tempo silencioso, com a censura vinculada às ditaduras, não deixaram de lutar por seus ideais de emancipação.

Um pouco mais tarde, na década de 70, houve, por parte das mulheres, uma retomada de consciência da importância de continuar a luta nos movimentos de libertação e na construção de políticas públicas, a necessidade de continuar construindo a história das mulheres como protagonistas.

Uma das grandes contribuições nesse processo de busca pela emancipação feminina deve-se à educação popular. Ressalta-se aqui a pedagogia de Paulo Freire, sobretudo a sua obra "A Pedagogia da Autonomia" (1996). Para o autor, a educação é indispensável para inserir as pessoas na sociedade e esta lhes dá condições de sentirem-se e atuarem como sujeitos da história, intervindo na realidade,

[...] é possível nos tornarmos capazes de intervir na realidade, tarefa incomparavelmente mais complexa e geradora de novos saberes do que simplesmente nos adaptar a ela. É por isso também que não me parece possível nem aceitável a posição ingênua ou, pior, astutamente neutra de quem estuda, seja o físico, o biólogo, o sociólogo, o matemático, ou o pensador da educação. Ninguém pode estar no mundo, com o mundo e com os outros de forma neutra (FREIRE, 1996, p. 77).

A educação crítica é aquela em que o educador ou a educadora entende definitivamente de que "ensinar não é transferir conhecimento, mas criar as 
possibilidades para a sua produção ou a sua construção" (FREIRE, 1996 p. 22), levando às pessoas a reflexões também críticas sobre a relação Teoria/Prática. Esse tipo de educação ajuda o ser humano na libertação dos condicionamentos que lhes são impostos pelas tradições, pelas diferentes ideologias midiáticas, pela alienação do consumismo competitivo e, principalmente, pelos preconceitos.

A respeito da educação tão almejada pelas mulheres no mundo todo, percebem-se as várias conquistas que foram permeando a trajetória de superação das dificuldades. À medida que elas foram superando os condicionamentos impostos pelas estruturas patriarcais, essas guerreiras foram e continuam na sua busca de engajamento político, profissionalismo, participação nos movimentos sociais, políticas públicas e nos vários setores da sociedade. O processo de libertação vai acontecendo e elas passam a assumir a educação que antes era acentuada nos moldes da mentalidade machista.

Embora sejam significativas e de grande contribuição as inúmeras conquistas resultantes das organizações das mulheres, encontramo-nos ainda em um sem fim de situações bárbaras cometidas contra elas e/ou por si mesmas. Isso se deve ao não entendimento de que a sociedade deve ser construída com a capacidade de homens e mulheres que têm potenciais e dignidade para a construção de uma sociedade humana na qual o respeito seja o elo de unidade entre os seres humanos na vivência menos competitiva e menos violenta. Esse deve ser o entendimento da construção do caminho de equidade entre homens e mulheres, na promoção da vida e de qualidade da mesma.

Nas palavras de Gebara (2015) ${ }^{13}$, a diferença de gênero é uma diferença entre uma multiplicidade de diferenças: diferenças entre homens e mulheres, entre homens e homens e entre mulheres e mulheres. Essas diferenças cruzam-se com as diferenças de idade, de cultura, de religião e muitas outras. Em entrevista com Maria José Rosado Nunes, Ivone Gebara responde que:

\section{[...] grande parte das teólogas feministas brasileiras alia seu trabalho}

\footnotetext{
${ }^{13}$ Ivone Gebara, religiosa da Congregação das Irmãs de Nossa Senhora Cônegas de Santo Agostinho, doutora em Filosofia e Ciências Religiosas. Ela é uma das expoentes da Teologia Feminista (TF) brasileira.
} 


\begin{abstract}
acadêmico e produção intelectual a uma militância nos movimentos sociais. Essa militância ocorre, sobretudo, na forma de assessoria aos movimentos populares ou na forma de cursos regulares dados, por exemplo, ao MST, ao movimento de trabalhadoras rurais, movimento de domésticas, grupos de mulheres da periferia, grupos de consciência negra, quadros sindicais femininos, etc. Essa inserção social e política da teologia feminista nos movimentos de base vem permitindo uma abordagem interdisciplinar a partir de vivências concretas, assim como um desenvolvimento exterior às instituições oficiais de reprodução das igrejas. Começamos a perceber que a busca de espiritualidade e de coerência ética não se situa apenas no interior das instituições da religião. Nesse sentido, também a Teologia Feminista no Brasil se expressa de forma plural, e é este pluralismo que faz sua riqueza e originalidade (GEBARA, 2005).
\end{abstract}

As mulheres, praticamente, em todas as culturas, em tempos remotos, ocupavam os espaços determinados pelos homens. Na atualidade, já existe a consciência de que elas precisam estabelecer relações que lhes dê protagonismo. Vêse, na prática, a diversidade de expressões e ações das mulheres que se fazem presentes em todos os recantos do Brasil e integram-se aos contextos socioeconômicos, políticos e religiosos. Elas revelam que a busca pela emancipação, pela mística e pela ética no mundo, não é algo novo, embora, carregue em si a novidade da busca diária e do fazer-se novo a cada respiro da existência humana.

O fato de unir a militância nos Movimentos sociais e outros Movimentos de libertação ao trabalho de produção intelectual possibilita uma interdisciplinaridade e ajuda os seres humanos na grande tarefa de transformação das relações de poder dentro das instituições religiosas, sociais, políticas e econômicas.

Gebara (2005) deixa claro que a teologia feminina ajuda a entender a ação das mulheres em diferentes sociedades, desde as profetizas que são mencionadas na Bíblia. A matriz ética, presente nos profetas e profetizas e na tradição de Jesus, é retomada igualmente pela Teologia Feminista.

Entretanto, a maior parte das teologias feministas separa-se, de certa forma, da teologia masculina da libertação, quando se trata da manutenção dogmática patriarcal, das imagens de Deus masculinas e de um conceito estrito que inclui apenas a pessoa individual de Jesus de Nazaré. Não se pode fazer Teologia Feminista sem falar dos corpos femininos e especificamente da sexualidade feminina.

Essa teóloga feminista acrescenta ainda que é a partir do corpo e da sexualidade que começa a opressão e a posse masculina em relação à mulher, embora seja aí, também, que se afirma a autonomia feminina. Ela insiste que 
a abordagem feminista das relações de gênero deve ser explicada com o viés da dominação, a partir da sexualidade que se expressa por meio da divisão injusta do trabalho social e doméstico, da legislação que mantém não apenas os privilégios de classe e de etnia, mas também os privilégios de gênero.

\section{Considerações finais}

As relações de poder estabelecidas pelo individualismo contemporâneo reforçam a falta de respeito às diferenças culturais e banalizam os conflitos e os acontecimentos de massacre e de exploração do ser humano que continuam ocorrendo a olhos vistos.

Essas relações de poder perpassam o tempo e continuam significativamente, com o estigma de uma mentalidade do patronato escravocrata revigorado no sistema patriarcal. As exigências de submissão, recato e docilidade impostas às mulheres produziram ao longo da história um poder simbólico, estruturando uma mentalidade que relegava o sexo feminino ao âmbito do lar, onde sua tarefa seria a de cuidar da casa, dos filhos e do marido e, passivamente, cumprir as suas decisões.

Esse poder determinante nas relações, gerando as desigualdades em vários âmbitos da convivência humana, passa a ser questionado e as mulheres têm contribuído significativamente na mudança dessa forma de pensar nos vários contextos da existência e atuação das mulheres. Isso vem ocorrendo desde o ambiente da academia aos espaços de sua atuação em movimentos populares.

Um, entre tantos exemplos de busca por direitos humanos das mulheres, no sentido prático, situamos a Economia Popular e Solidária que tem contribuído para estabelecer uma participação maior em espaços diferentes de trabalhos, como fonte de renda para atender as necessidades básicas. Além de ser um espaço de construção de uma nova mentalidade, que possibilita autonomia das mulheres, a Economia Popular e Solidária reforça a capacidade de gerir uma economia também fora de seus lares.

Conscientes do papel que assumem na sociedade, unem-se aos saberes de mulheres que também foram críticas no decorrer da história para continuarem incansavelmente no processo de emancipação. Toda a contribuição das mulheres que 
foram apresentadas no desenvolvimento deste trabalho e que marcaram com êxito seus espaços, deve-se ao fato de buscarem incansavelmente descontruir muitos conceitos culturais e legais, que foram profundamente prejudiciais e danosos para a vida das mulheres.

\section{Referências}

ADJAMAGBO Agnès, CALVÈS Anne-Emmanuèle. A emancipação feminina sob restrição, Autrepart, 2012/2 (N 61), p.3-21. DOI: 10.3917/ autr.061.0003

ARISTÓTELES. Politics. Trad. de H. Rackham. Londres: Loeb Classical Library, 2005.

ASSUMANN, Severino José. Declaração dos direitos da mulher e da cidadã. Olympe de Gouges (1791), Revista Interdisciplinar Interthesis, Florianópolis: 2007.

BALIERO, Cristina. Mulheres Marcantes: Carlota Pereira de Queirós (1892-1982). 2014. Disponível em: https://femininosagrado.com.br/mulheres-marcantes-carlotapereira-de-queiros-18921982/. Acesso: 15 fev. 2016.

BEAUVOIR Simone (de), Le Deuxième Sexe, Paris, Gallimard, 1976 (1949).

BEAUVOIR, Simone de. O Segundo Sexo, v. I, II. Tradução Sérgio Milliet. Rio de Janeiro: Nova Fronteira, 1980.

BERIS, Francine. Simone de Beauvoir et Le Deuxième Sexe. In: GALSTER, Ingrid. Le Deuxième Sexe de Simone Bauvoir. Paris: Presses Paris Sorbonne, 2004.

CARVALHO, José Murilo de. Cidadania no Brasil: o longo caminho. 14. ed. Rio de Janeiro: Civilização Brasileira, 2011.

FREIRE, Paulo. Pedagogia da autonomia: saberes necessários à prática educativa. São Paulo: Paz e Terra, 1996.

FREITAS, Maria Ester de. Especial Mulheres: Mulheres e administração, Vol. 5, №2, p.1- Maio/jun. 2006. http://bibliotecadigital.fgv.br/. Acesso em: 23 mar. 2017.

GEBARA, Ivone. Teologia feminista e a crítica da razão religiosa patriarcal. Entrevista com Maria José Rosado Nunes. PUCSP, 2005.

GONÇALVES, Luiz Alberto Oliveira; SILVA, Petronilha Beatriz Gonçalves. Movimento 
negro e educação. Rev. Bras. Educ., №.15, Rio de Janeiro, sept./dec. 2000.

GOUGES, Olympe de. Déclaration des droits de la femme et de la citoyenne. In: Bibliothèque Jeanne Hersch. Textes fondateurs. Disponível em:

http://www.aidh.org/Biblio/Text_fondat/FR_03.htm. Acesso em: 16 out. 2020.

MANO, Maíra Kubík. As mulheres desiludidas: de Simone de Beauvoir à "ideologia de gênero". Cadernos Pagu, n. 56, 2019, p.04. Disponível

em:https://www.scielo.br/pdf/cpa/n56/1809-4449-cpa-56-e195624.pdf. Acesso em: 01 nov. 2020.

MOTTA, Débora. História Ciência Saúde. Boletim da Faperj/ Set. 2014, p. 02. Disponível: http://www.revistahcsm.coc.fiocruz.br/pesquisa-analisa-insercao-dasmulheres-no-ensino-superior-no-rio-de-janeiro/. Acesso em: jan. de 2017.

MURARO, Rose Marie. A Mulher no Terceiro Milênio. Rio de Janeiro: Rosa dos Tempos, 1993.

RIBEIRO, Cristiane. A Emancipação e participação política das mulheres na segunda metade do século XIX no Brasil. Disponível em:

http://www.en.wwc2017.eventos.dype.com.br/resources/anais/1503517850_ARQUIV O_FazendoGenero.pdf. Acesso em: 29 out. 2020.

ROCHA, Marlos Bessa Mendes de. O ensino elementar no Decreto Leôncio de Carvalho: "visão de mundo" Revista Brasileira de Educação v. 15 n. 43 jan./abr. 2010.

\section{SANTO, A.R.T. Tratado Sobre Emancipação Política da Mulher e Direito de}

Votar. Rio de Janeiro: Typografia Paula Brito, 1868. P. 73. Disponível em: https://digital.bbm.usp.br/view/?45000010736\&bbm/6702\#page/12/mode/2up. Acesso em: 31 out. 2020.

SCHPUN, Mônica Raisa. Carlota Pereira de Queiroz: uma mulher na política. Revista Brasileira de História; v.17; n³3; 1997; p. 167-200; São Paulo.

SCHUMAHER, Schuma; BRAZIL, Érico Vital (Orgs: de 1500 até a atualidade. Rio de Janeiro: Jorge Zahar Ed., 2000.

SOIHET, Rachel. A pedagogia da conquista do espaço público pelas mulheres e a militância feminista de Bertha Lutz. Rev. Bras. Educ. nํ. 15 Rio de Janeiro.

Set./dez. 2000. Disponível em: http://www.scielo.br/scielo. Acesso em: 20 jan.2017.

ZUCCO, Luciana; LISBOA, Teresa Kleba. Rose Marie Muraro: uma mulher impossível. Rev. Estud. Fem., v. 22, n. 2, p. 563-564, 2014. 
Manuscrito recebido em: 18 de outubro de 2020

Aprovado em: 10 de novembro de 2020

Publicado em: 15 de novembro de 2020 